RELIABILITY AND MAINTAINABILITY IN PERSPECTIVE 


\begin{abstract}
Also by the same author
\end{abstract}
Reliability Engineering, Pitman, 1972

Maintainability Engineering, Pitman, 1973 (with A. H. Babb)

Statistics Workshop, Technis, 1974

Engineering Quality Software, Elsevier, 1987 (with K. B. Wood) 


\title{
Reliability and Maintainability in Perspective
}

\author{
Practical, contractual, \\ commercial and software aspects
}

David J Smith

B.Sc.,C.Eng, F.I.E.E., F.I.Q.A., F.Sa.R.S., M.I.Gas E.

Third Edition

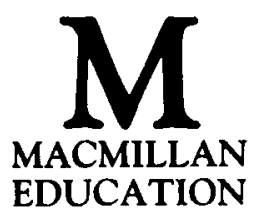


All rights reserved. No reproduction, copy or transmission of this publication may be made without written permission.

No paragraph of this publication may be reproduced, copied or transmitted save with written permission or in accordance with the provisions of the Copyright Act 1956 (as amended), or under the terms of any licence permitting limited copying issued by the Copyright Licensing Agency, 33-4 Alfred Place, London WC1E 7DP.

Any person who does any unauthorised act in relation to this publication may be liable to criminal prosecution and civil claims for damaged.

First edition 1981

Second edition 1985

Third edition 1988

Published by

MACMILLAN EDUCATION LTD

Houndmills, Basingstoke, Hampshire RG21 2XS

and London

Companies and representatives

throughout the world

British Library Cataloguing in Publication Data

Smith, David J.

Reliability and maintainability in perspective : practical, contractual, commercial and software aspects. - 3rd ed.

1. Electronic apparatus and appliances. - Reliability

2. Maintainability (Engineering)

I. Title

621.381'042 TK7870

ISBN 978-1-349-10142-9

ISBN 978-1-349-10140-5 (eBook)

DOI 10.1007/978-1-349-10140-5 


\section{Contents}

Introduction to the Second Edition ix

Introduction to the Third Edition $\quad$ xi

Acknowledgements xii

Part I: Understanding Terms, Parameters and Costs 1

1. How Important are Reliability and Maintainability? 3

1.1 Past and present; 1.2 Reasons for interest; 1.3 Activities involved;

1.4 Contractual problems

2. A Realistic Approach is Cost Conscious

2.1 Cost of quality and reliability; 2.2 Introducing a quality cost system; 2.3 User quality costs; 2.4 Cost and performance;

2.5 Relative defect costs; 2.6 The complex equation

3. Understanding Terms and Jargon

3.1 Failure, failure mode and Reliability; 3.2 Failure rate and Mean Time Between Failures; 3.3 Interrelationships of Reliability, $\lambda, \theta ; 3.4$ The Bathtub Distribution; 3.5 Down Time and Repair Time; 3.6 Availability; 3.7 Choosing the appropriate parameter

Part II: Achieving Reliability and Maintainability Objectives

4. Design and Assurance for Reliability

4.1 Inherent design levels; 4.2 Activities in design; 4.3 Assurance activities

5. Design Factors Influencing Down Time

5.1 to 5.17 cover 17 key design areas from 'Access' to 'Test Points' 
vi Contents

6. Maintenance Philosophy and Down Time

6.1 Organisation of maintenance resources; 6.2 Maintenance procedures; 6.3 Tools and test equipment; 6.4 Personnel considerations; 6.5 Maintenance instructions; 6.6 Spares provisioning;

6.7 Logistics; 6.8 The user and the designer; 6.9 Computer aids to maintenance

7. Reliability Analysis and Failure Mechanisms

7.1 Stress and failure; 7.2 Failure Mode and Effect Analysis;

7.3 Fault Tree Analysis; 7.4 FMEA, FTA, parts count and simulation;

7.5 Failure mechanisms

8. Design and Qualification Testing

8.1 Categories of testing; 8.2 Environmental testing; 8.3 Marginal testing; 8.4 High reliability testing; 8.5 Reliability growth testing; 8.6 Testing for packaging and transport; 8.7 Multiparameter testing;

8.8 Demonstration testing; 8.9 Test houses

9. Quality Assurance and Automatic Test Equipment

9.1 Functions of quality assurance; 9.2 Automatic test equipment

\section{Maintenance Handbooks}

10.1 The need for maintenance manuals; 10.2 A typical maintenance philosophy; 10.3 Information requirements for each group; 10.4 Types of manual; 10.5 Computer-aided fault finding; 10.6 The manual in perspective

\section{Making Use of Field Feedback}

11.1 Reasons for collecting field data; 11.2 Information to be recorded; 11.3 Difficulties involved; 11.4 Analysis and presentation of results; 11.5 Examples of failure report forms

\section{Part III: Making Measurements and Predictions}

12. Interpreting Data and Demonstrating Reliability

12.1 Inference and confidence levels; 12.2 The $\chi^{2}$ test; 
12.3 Double-sided confidence limits; 12.4 Summarising the $\chi^{2}$ test;

12.5 Reliability demonstration; 12.6 Sequential testing; 12.7 Setting up demonstration tests; Exercises

13. Interpreting Variable Failure Rate Data by Probability Plotting

13.1 The Weibull distribution; 13.2 Using the Weibull method;

13.3 More complex cases of the Weibull distribution;

13.4 Continuous processes; Exercises

14. Demonstrating Maintainability

14.1 Demonstration risks; 14.2 US MIL STD 471A; 14.3 Data collection

15. Reliability Prediction and Modelling

15.1 Why carry out reliability predictions?; 15.2 Methods of prediction; 15.3 The approach to block diagram analysis; 15.4 Probability theory; 15.5 Reliability of series systems; 15.6 Reliability with active redundancy; 15.7 General types of redundant configuration; 15.8 Redundant systems with repair of failed units; 15.9 The Markov model for repairable systems; 15.10 Allowing for common cause failures; 15.11 Prediction in perspective; Exercises

16. Prediction of Repair Times

16.1 Methods of prediction; 16.2 US MIL HANDBOOK 472 Procedure 2; 16.3 US MIL HANDBOOK 472 - Procedure 3; 16.4 Checklist - MIL 472 - Procedure 3; 16.5 Another checklist method

17.1 Setting objectives and specifications; 17.2 Planning, feasibility and allocation; 17.3 Programme activities; 17.4 Responsibilities 
18. Contract Clauses and their Pitfalls

18.1 Essential areas; 18.2 Other possible areas; 18.3 Pitfalls;

18.4 Penalties; 18.5 Subcontracted reliability assessments;

18.6 Example

19. Product Liability and Safety Legislation

19.1 The general situation; 19.2 Strict liability; 19.3 The Consumer Protection Act, 1987; 19.4 Health and Safety at Work Act, 1974;

19.5 Insurance; 19.6 Product recall; 19.7 Industrial hazards

20. A Case Study: The Datamet Project

20.1 Introduction; 20.2 The Datamet Concept; 20.3 Formation of the project group; 20.4 Reliability requirements; 20.5 First design review; 20.6 Design and development; 20.7 Syndicate study; 20.8 Hints

21. Software Reliability and Quality Assurance

21.1 The effect of programmable devices on reliability;21.2 Software failures; 21.3 Software failure modelling; 21.4 Software quality assurance; 21.5 The way forward;21.6 Data communications; 21.7 Software QA checklists

22. Failure Rates and Failure Modes

22.1 Data sources; 22.2 The general failure rates; 22.3 The microelectronic failure rates; 22.4 The other tables

Table 1 General failure rates

Table 2 Microelectronic failure rates

Table 3 Fatality rates

Table 4 Human error rates

Table 5 Percentage failure modes

Appendix 1. Glossary

Appendix 2. Percentage points of the $\chi^{2}$ distribution 266

$\begin{array}{ll}\text { Appendix 3. Bibliography } & 270\end{array}$

Appendix 4. Answers to exercises $\quad 272$

$\begin{array}{ll}\text { Index } & 276\end{array}$

Failure Rate Data on Disc - details $\quad 279$ 


\section{Introduction to the Second Edition}

It is the combination of Reliability and Maintainability which dictates the proportion of time that any equipment will be available for use. The two key parameters are Failure Rate and Down Time and they determine the user's failure costs in operating the product. For the manufacturer they will determine the cost of warranty and redesign, and also influence his prestige in the market place. A single defect can cost $£ 50$ in diagnosis and replacement if detected in the factory, while the same fault in the field will cost upwards of $£ 200$ to rectify. An hour of down time of a communications link can represent a lost revenue of at least $£ 1000$ whereas a spurious fire alarm on an oil production platform may cost 100 times that figure in lost production. This book emphasises the importance of setting realistic targets which lead to savings in excess of the design costs involved.

Reliability and Maintainability clauses in contracts for both system design and for off the shelf products are now commonplace. In the defence, telecommunications and aerospace fields these requirements have been specified for many years. More recently, contracts for equipment in the oil and gas industry have tended to stipulate reliability and repair requirements. Chapters 18 and 19 are devoted to contractual and legal topics.

Admittedly, defects can be 'inspected out', albeit at an unrealistic cost, but failure-free performance can result only from inherent reliability in design. It cannot be over-stated that satisfying such requirements is largely a matter of good engineering practice and the application of formal controls in design, manufacturing and service. The major part of this book deals with quantifying and achieving Reliability and ease of repair.

Computers have now entered every field and reliability is no exception. This book discusses the areas where computers can be used as reliability design aids. The increasing use of computer control in the form of microprocessors, now used in products from washing machines to petrol pumps, from telephone switching to motor vehicles, brings the possibility of failure due to the unforeseen behaviour of the software. Chapter 21 is devoted to the techniques used to minimise softwarerelated failures.

The mathematical aspects of the subject, although important, do not themselves create more reliable or more easily maintained products. Too often the author has had to discourage efforts to refine reliability predictions and precisely define failure rates when an order of magnitude estimate would have sufficed. In all areas 
of engineering the ability to recognise the degree of accuracy required is of the essence. Chapter 15 provides all the theory necessary for reliability prediction and the use of suitable approximations where appropriate.

Since we are dealing with engineering parameters a practical, cost-related, approach is essential. There is a cost to achieve any parameter as well as a cost associated with each failure. The aim is to select and to achieve levels of failure rate and repair time which keep the total of these costs at a minimum. Only in this way can reliability justify its place in the spectrum of activities.

A feature of this edition is the inclusion of a data bank (chapter 22) of failure rates for the full range of engineering and microelectronic components. In addition there are tables of human risks, human error rates and the percentage failure modes of components. The majority of the figures are expressed as ranges rather than single values.

The views and data expressed in this book are the result of the author's 20 years experience in industry and do not represent the opinions or data of any one organisation. 


\section{Introduction to the Third Edition}

The failure rate ranges in chapter 22 have proved to be a popular feature of the Second Edition. Since then, US MIL 217E has replaced 217D and British Telecom HRD4 has superseded HRD3. A great deal of other data has also become available and, therefore, the failure rate section has been completely revised, as has the FARADIP disc which is available from Macmillan Education and from the author.

The year of 1987 saw the implementation of strict liability via the Consumer Protection Act. As a result, chapter 19 has been extensively revised.

Software reliability is attracting more and more interest, and thus chapter 21 has been updated.

The recent CIMAH (Control of Industrial Major Accident Hazards) Regulations (UK) impose a requirement on designers and users of plant to analyse and assess the performance of their equipment. Thus the techniques of Reliability prediction and design received yet another impetus. 


\section{Acknowledgements}

I would particularly like to thank the following friends and colleagues for their patient help and encouragement with the second edition.

My very good friend Len Nohre for his meticulous checking of the revised manuscript and for his many helpful suggestions.

My friend and colleague John Catchpole for checking the manuscript and for suggesting some useful additions.

Tony Fisher, of Field Fisher \& Martineau, for his astute comments and help with revising the legal and contractual chapters.

Alex Babb, co-author of Maintainability Engineering (Pitman, 1973), for permission to quote freely from those pages.

George Knight with whom I have enjoyed numerous stimulating conversations on the subject.

My dear wife, Margaret, who has much to contend with.

I would also like to thank the Civil Aviation Authority and ITT Europe for permission to reproduce their failure report forms and the US Department of Defense for permission to quote from MIL Handbooks.

I would like to thank the following people for help with the third edition.

Rodney Nelson-Jones of Field Fisher \& Martineau for help with the revisions to chapter 19 in view of the Consumer Protection Act.

Niall O'Connor for calculating the revised US MIL 217E microelectronic failure rates which were needed in order to update the failure rate ranges in chapter 22 . 